\title{
ON THE APPLICATION OF THE WEAK-BEAM TECHNIQUE \\ TO THE DETERMINATION OF THE SIZES OF SMALL POINT-DEFECT CLUSTERS IN ION-IRRADIATED COPPER*
}

\author{
M. L. Jenkins ${ }^{1}$, M. A. Kirk ${ }^{2}$, and H. Fukushima ${ }^{3}$ \\ ${ }^{1}$ Dept. of Materials \\ University of Oxford \\ Parks Rd., Oxford OX1 3PH, UK \\ ${ }^{2}$ Materials Science Division \\ 9700 S. Cass Avenue \\ Argonne National Laboratory \\ Argonne, IL 60439 \\ ${ }^{3}$ Faculty of Engineering \\ Hiroshima University \\ Higashi-Hiroshima 739-8527, Japan
}

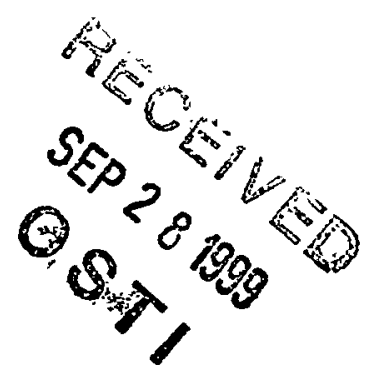

October 1998

The submitted manuscript has been created
by the University of Chicago as Operator of
Argonne National Laboratory (Argonne")
under Contract No. W-31-109-ENG-38 with
the U.S. Department of Energy. The U.S.
Government retains for itself, and others
acting on its behalf, a paid-up, non
exclusive, irrevocable worldwide license in
said article to reproduce, prepare derivative
works, distribute copies to the public, and
perform publicly and display publicly, by or
on behalf of the Government

Paper to be submitted to the Symposium on High Voltage Electron Microscopy for $21^{\text {st }}$ Century and Its Application to Frontier Materials Study, October 15-17, 1998, Sapporo, Japan.

*Work supported by the U.S. Department of Energy, Basic Energy Sciences-Materials Sciences, under contract \#W-31-109-ENG-38. 


\section{DISCLAIMER}

This report was prepared as an account of work sponsored by an agency of the United States Government. Neither the United States Government nor any agency thereof, nor any of their employees, make any warranty, express or implied, or assumes any legal liability or responsibility for the accuracy, completeness, or usefulness of any information, apparatus, product, or process disclosed, or represents that its use would not infringe privately owned rights. Reference herein to any specific commercial product, process, or service by trade name, trademark, manufacturer, or otherwise does not necessarily constitute or imply its endorsement, recommendation, or favoring by the United States Government or any agency thereof. The views and opinions of authors expressed herein do not necessarily state or reflect those of the United States Government or any agency thereof. 


\section{DISCLAIMER}

Portions of this document may be illegible in electronic image products. Images are produced from the best available original document. 


\section{On the application of the weak-beam technique to the determination of the sizes of small}

point-defect clusters in ion-irradiated copper

Michael L Jenkins ${ }^{1}$, Marquis A Kirk ${ }^{2}$ and Hiroshi Fukushima ${ }^{3}$

1. Department of Materials, University of Oxford, Parks Rd.,Oxford OX1 3PH, U.K. Tel: 441865273655 ; Fax: 441865273789 ; mike.jenkins@materials.oxford.ac.uk

2. Materials Science Division, Argonne National Laboratory, Illinois 60439, U.S.A. Tel 630252 4998; Fax 630252 4289; kirk@anl.gov

3. Faculty of Engineering, Hiroshima University, Higashi-Hiroshima 739-8527, Japan Tel: +81-824-24-7857; Fax: +81-824-22-7192; hirofk@ipc.hiroshima-u.ac.jp

Running title: Weak-beam microscopy for determining point-defect cluster sizes

keywords: weak-beam microscopy, defects, clusters, irradiation damage

Contributor dealing with correspondence: Jenkins

16 Pages and 6 Figures 
We have made an analysis of the conditions necessary for the successful use of the weak-beam technique for identifying and characterising small point-defect clusters in ion-irradiated copper. The visibility of small defects was found to depend only weakly on the magnitude of the beamconvergence. In general, the image sizes of small clusters were found to be most sensitive to the magnitude of $s_{g}$, with the image sizes of some individual defects changing by large amounts with changes in $\mathrm{s}_{\mathrm{g}}$ as small as $0.025 \mathrm{~nm}^{-1}$. The most reliable information on the true defect size is likely to be obtained by taking a series of 5-9 micrographs with a sȳstematic variation of deviation parameter from $0.2-0.3 \mathrm{~nm}^{-1}$. This procedure allows size information to be obtained down to a resolution limit of about $0.5 \mathrm{~nm}$ for defects situated throughout a foil thickness of $60 \mathrm{~nm}$. The technique has been applied to the determination of changes in the sizes of small defects produced by a low-temperature in-situ irradiation and annealing experiment.

\section{Introduction}

In many radiation-damage studies it is necessary to identify, count and size by transmission electron microscopy point-defect clusters as small as 1-4 nm. This presents considerable difficulty, especially for defects placed throughout foils of thickness $20-80 \mathrm{~nm}$. It has long been known that the weak-beam dark-field technique has advantages over conventional strong-beam methods for imaging small clusters, for example in imaging and sizing loops of diameter $>5 \mathrm{~nm}$ [1] or gaining information on the morphology of complex clusters such as partially-dissociated Frank loops [2]. However, the technique has certain drawbacks when the defect sizes are very small (see section 2.1 below). The primary purpose 
of the present paper is to present a thorough investigation of this technique as applied to defects in copper. We analyse images as functions of diffraction vector, deviation parameter, and beam convergence angle, in order to determine the conditions necessary for accurate sizing. We go on to describe the application of the technique to an in-silu low-temperature experiment in heavy-ion irradiated copper.

\section{Counting and sizing of small point-defect clusters under weak-beam conditions.}

2.1 Difficulties with the conventional technique and possible improvements.

The visibility of small point-defect clusters is generally considerably better under weakbeam diffraction conditions than under strong two-beam or kinematical bright-field conditions. This has prompted many researchers to use weak-beam conditions for counting and sizing small clusters (for a recent example see ref [3]). However, it has long been recognised that the technique is not without problems, especially for defects smaller than the effective extinction distance $\xi_{\mathrm{g}}{ }^{\text {eff }} \approx\left|\mathrm{s}_{\mathrm{g}}\right|$. Generally, analyses are made from a single micrograph. The operating reflection is often chosen such that most or all dislocation loops should be in contrast (i.e. g.b $\neq 0$ ). In fcc materials the usual choice is $g=002$, which in principle images all Frank loops and stacking-fault tetrahedra (SFT), and most perfect loops. The difficulties which can arise from this approach are exemplified if the same field of small defects is imaged under several similar weak-beam conditions, differing only in the exact value of $\left|s_{\mathrm{g}}\right|$. This experiment is shown explicitly in section 2.2 below, but can be summarised as follows: 
(i) The magnitude of the contrast of individual defects may vary significantly with small variations in $\left|s_{g}\right|$. Some defects may even be completely invisible in one micrograph, but show clear contrast in another taken under very similar diffraction conditions.

(ii) The image size may vary significantly with small variations in $\left|s_{g}\right|$. Clearly the image size of a defect under any one diffraction condition may not be a good measure of the true size of the defect.

These difficulties have led some authors to advocate that weak-beam images should not be used at all for counting and sizing small defects $[4,5,6]$. However, other diffraction conditions seem even less favourable. For example, the visibility of small defects under the kinematical diffraction conditions recommended by, say, Haüssermann et al [4] is found in practice to be much poorer than under weak-beam conditions. Satoh et al [7] have suggested a possible solution to the problem. These authors carried out theoretical and experimental studies of the diffraction contrast of small stacking-fault tetrahedra (SFT). They confirmed that the images of SFT under weak-beam conditions are dominated by stacking-fault fringes arising from the triangular inclined faces of fault, with the stair-rod dislocations making. only a minor contribution to the total contrast (see also ref [6] ). Small SFT, of size $\geq \xi_{\mathcal{g}}^{\text {eff }} \approx 5 \mathrm{~nm}$., show just one fringe from each inclined face. Somewhat larger SFT show two or more fringes. The images are generally smaller than the true SFT size, and are dependent on factors such as $\left|s_{g}\right|$, the foil thickness and defect depth. These dependencies are easily understood. For different values of $\left|s_{g}\right|$, the fringes are displaced in depth, moving up or down the face of the fault. Satoh et al [7] suggested that if micrographs were recorded for several different values of $\left|s_{g}\right|$ the longest fringe might be expected to correlate reasonably well to the maximum extent of the fault. The maximum image size should therefore be taken to correspond to the true SFT size. 
Experimental studies of small $(\sim 2 \mathrm{~nm})$ SFT in quenched silver imaged under a wide range of $\left|s_{g}\right|$, from two-beam $\left(\left|s_{g}\right|=0\right)$ to weak-beam with $\left|s_{g}\right|=0.3 \mathrm{~nm}^{-1}$, were in good accord with this hypothesis. The image sizes of individual SFT varied with deviation from the Bragg condition, but in each case showed a well-defined maximum. Overall, the visibility was best for $\left|s_{g}\right| \geq 0.2$ $\mathrm{nm}^{-1}$, but the average image sizes of about 300 SFT was only weakly dependent on $\left|s_{g}\right|$.

In the current work we were primarily concerned with characterising very small (2$4 \mathrm{~nm}$ ) clusters in ion-irradiated copper. We seek a method of determining the sizes of these small defects reliably, or at least of being able to detect changes in defect sizes, for example on annealing. In order to investigate if this is possible, we have made a careful experimental analysis of weak-beam images as functions of diffraction vector, deviation parameter, and beam convergence angle. The results are described in the next section.

\subsection{Experimental investigation of the weak-beam contrast of small clusters}

The specimens chosen for analysis were copper foils which had been irradiated at room temperature with $\mathrm{Cu}^{+}$ions of energy $600 \mathrm{keV}$ in order to produce high energy collision cascades uniformly throughout a thickness of $\sim 60 \mathrm{~nm}$. The ion dose was about $10^{15}$ ions $\mathrm{m}^{-2}$ so that individual ion impacts were generally well separated. The ion energy was chosen such that the primary knock-on spectrum resembled that produced by fission neutrons. The irradiation was performed along the direction of the foil normal, which was close to [111], and the specimen was tilted close to the $<110>$ pole for imaging. This had the effect that multiple clusters strung along the path of an incoming ion were separated spatially in the images. Similar ion irradiation conditions were also used in the in-situ low-temperature experiment described in section 3 below. 
The specimens were imaged in a Philips CM30 microscope, operating at $100 \mathrm{kV}$ rather than its top voltage of $300 \mathrm{kV}$ in order to avoid electron-beam damage. A flat region of foil of thickness $\sim 50 \mathrm{~nm}$ (subsequently determined explicitly by convergent-beam diffraction) was selected. The defect clusters produced by the ion irradiation were found to have sizes mostly in the range $2-4 \mathrm{~nm}$. A minority of these clusters may be complete SFT, but most are likely to be small, probably dissociated, Frank loops or perfect loops. The majority were visible under weak-beam conditions only as more or less structureless white dots and a determination of the exact defect morphology was not possible. A series of seven to nine weak-beam images was recorded for each of the following sets of conditions (i)-(vi). For conditions (ii)-(vi) the images were all of the same field of defects giving a total of about 40 micrographs of the same area. The direct magnification was $8.9 \times 10^{4}$ and typical exposure times ranged from $2-4 \mathrm{~s}$ with Kodak SO 163 film, developed for 10 mins in concentrated D19 developer in order to increase the film speed by a factor of about four.

(i) $\mathrm{g}=002, \mathrm{~s}_{\mathrm{g}}>0$, with $\left|\mathrm{s}_{\mathrm{g}}\right| \approx 0.25 \mathrm{~nm}^{-1}$, and with the beam convergence semi-angle varying from $0.32^{\circ}$ to $0.16^{\circ}$.

(ii) $g=002, s_{g}>0$, with $\left|s_{g}\right|$ ranging in 7-9 approximately equal steps from $0.14-0.3$ $\mathrm{nm}^{-1}$. In the $(\mathrm{g}, \mathrm{ng})$ notation sometimes adopted to describe weak-beam imaging conditions (where the image is taken in the reflection $\mathrm{g}$ and the Ewald sphere cuts the line of systematic reflections at $\mathrm{ng}$ ), $\mathrm{n}$ varies from about 3.75 to 6.25 . The beam convergence semi-angle was held approximately constant $0.25^{\circ}$. The value of $\left|s_{g}\right|$ was set using a Kikuchi pattern formed with the selected-area aperture removed. Such 
patterns, from a flat foil, considerably facilitated the setting of the foil orientation, allowing $\left|s_{g}\right|$ to be set to an accuracy of $\pm 0.01 \mathrm{~nm}^{-1}$ (or $\mathrm{n}$ to an accuracy of 0.25 ).

(iii) as for (ii), but with $s_{\mathrm{g}}<0$.

(iv) as for (ii), but with $\mathrm{g}=00 \overline{2}$.

(v) as for (iii), but with $\mathbf{g}=00 \overline{2}$.

(vi) a series corresponding to condition (ii), but with the foil tilted about $15^{\circ}$ along the 002 Kikuchi band, so forming stereo pairs with the corresponding micrographs in series (ii).

Image size measurements were made using the following procedure. Each negative was printed to the same total magnification $5 \times 10^{5}$. The prints were selected in random order, placed in turn on a digitising tablet and examined through a $10 \mathrm{x}$ eyepiece. In general, the maximum extent of each image was measured, although care was taken always to measure the same defect in the same direction on each print. Each size measurement was repeated 10 times in order to improve the statistical accuracy. There is an inevitable subjective element in deciding the edge of the contrast figure. In order to try to reduce this problem, one author (MLJ) made all the measurements. Test measurements by the other authors showed small changes in absolute sizes, but confirmed the same trends.

This procedure was used first to investigate the effect of varying the beam convergence (condition (i) above), and the results are shown in Figures 1 and 2. Figure 1 shows 
micrographs of the same field of defects under different values of the beam convergence. The image sizes of a set of ten defects (labelled F-O on Figure 1) were followed as a function of the incident beam semi-angle for four values ranging from $0.32^{\circ}$ (a maximum defined by the largest available condenser aperture, and obtained by fully-focussing the beam) to $0.16^{\circ}$, corresponding to a change in exposure time from $0.5 \mathrm{~s}$ to $15 \mathrm{~s}$. The results of these measurements are shown in Figure 2. The statistical errors on the reproducibility of measurements are estimated to be about the size of the data points, and so error bars are not shown. It can be seen that there is a tendency for the measured defect sizes to decrease with decreasing beam convergence, but the effect is relatively weak. In practice, for all of the experiments described below the beam convergence was held fairly constant (with a beam semi-angle of about $0.25^{\circ}$ ). The beam convergence does not need to be set more exactly because of the weak dependence of the image sizes on this parameter. Note however that the measured image sizes are somewhat sensitive to the contrast level of the print. This can be seen from the two sets of points corresponding to a beam semi-angle of $0.32^{\circ}$ in Figure 2. These pairs of measurements were taken from prints of the same negative printed to different levels of contrast. In each case the harder contrast level resulted in a smaller measured image size. For this reason it is important to print all negatives on the same grade of paper to similar levels of contrast.

With these precautions taken, we now consider the effects of varying $s_{g}$ and $g$. Figure 3 shows a series of seven weak-beam micrographs corresponding to condition (ii), together with a dark-field two-beam $\left(s_{g}=0\right)$ micrograph. Conditions (iii)-(vi) show similar features, and so micrographs for these conditions are not shown separately. Note the much better visibility of the smaller defects under weak-beam conditions compared with 2-beam conditions. Under weak-beam conditions, most of the defects are visible as white dots with little if any fine 
structure. A few show linear or V-shaped features characteristic of near edge-on Frank loops and stacking-fault tetrahedra.

A set of 10 representative defects, imaged under conditions (ii)-(vi), was selected for quantitative size measurements. These defects are labelled 1-10 on the two bottom-right micrographs in Figure 3. The directions in which the size measurements were made are indicated by the directions of the arrows. The results of the size measurements are illustrated in Figure 4, which shows the measured image sizes for each defect, for $\pm \mathbf{g}$ and as a function of $s_{g}$. The results of stereo measurements of the depths of the defects in the foil (condition (vi)) are shown in Figure 5.

The main points which can be seen from Figures 3-5 are as follows:

- We can identify defects which show the contrast characteristics anticipated in the previous section. Thus defects \#1, 2 and 5 are visible in all seven weak-beam micrographs in Figure 3 with little change in contrast. Most of the other marked defects are also visible in most micrographs, although the strength of the contrast and the apparent size of the defect varies from one micrograph to another. Some defects disappear in at least one micrograph in Figure 3 (e.g. defects \# 9 and \# 3 are not visible for $\mathrm{s}_{\mathrm{g}}=0.27 \mathrm{~nm}^{-1}$ whilst defect \# 8 is also invisible for $\mathrm{s}_{\mathrm{g}}=0.27 \mathrm{~nm}^{-1}$ and shows very low visibility for $\mathrm{s}_{\mathrm{g}}=0.18 \mathrm{~nm}^{-1}$ ).

- Note that defects which show good visibility in Figure 3 for $\left(+g,+s_{g}\right)$ conditions do not necessarily show good visibility under other contrast conditions. Thus defect 1 , for example, is not visible for $\left(+\mathrm{g}-\mathrm{s}_{\mathrm{g}}\right)$ for $\mathrm{s}_{\mathrm{g}}=-0.24 \mathrm{~nm}^{-1}$, defect 2 is not visible for 
$\left(-g+s_{g}\right)$ for $s_{g}=0.21 \mathrm{~nm}^{-1}$, whilst defect 5 is not visible for two conditions, $\left(-\mathrm{g}, \mathrm{s}_{\mathrm{g}}\right.$ $\left.=0.18 \mathrm{~nm}^{-1}\right)$ and $\left(\mathrm{g}, \mathrm{s}_{\mathrm{g}}=-0.18 \mathrm{~nm}^{-1}\right)$, see Figure 4. Only one defect (\#10) is visible under all conditions, and at high values of $\left|s_{g}\right|$ this particular defect gave a double image, suggesting that it may consist of two closely-separated clusters.

- Individual defects show very considerable variations in image size. For the smallest defects the image size may change by $50-100 \%$ with a change in $\mathrm{s}_{\mathrm{g}}$ as small as 0.025 $\mathrm{nm}^{-1}$. These variations are much more marked than those seen with changes in the beam convergence semi-angle (Figures 1 and 2).

- Some defects (e.g. \# 1, 5, 6) show evidence of a weak inside-outside contrast effect in that a change in the sign of $g$ or in the sign of $s_{g}$ lead to a small, but perhaps systematic, variation in the measured image sizes. Overall, however, no defects show fully-consistent inside-outside behaviour with a change in the signs both of $\mathrm{g}$ and of $s_{g}$.

- The biggest variations in image size are often seen for $\left|\mathrm{s}_{\mathrm{g}}\right|<0.2 \mathrm{~nm}^{-1}$. The image size is also often largest for $\left|s_{g}\right|<0.2 \mathrm{~nm}^{-1}$

- Some defects (e.g. \#9, 10) show apparent oscillations in contrast with $s_{\mathrm{g}}$ Others (e.g. \# 2,3) show much smaller variations in size through the series of micrographs, especially for $\left|s_{g}\right|>0.2 \mathrm{~nm}^{-1}$.

- Most defects show a reasonably consistent maximum image size for values of $\left|s_{g}\right|$ in the range $0.2-0.3 \mathrm{~nm}^{-1}$. This suggests that the maximum image size for $\left|\mathrm{s}_{\mathrm{g}}\right|>0.2$ 
$\mathrm{nm}^{-1}$ may be the most appropriate measure of the true defect size as recommended by Satoh et al [7] for SFT. However, this conclusion cannot be confirmed without detailed image simulations, which will have to take into account the probable complex defect geometry. The maximum image size can typically be measured to an accuracy of about $0.5 \mathrm{~nm}$.

- Stereo microscopy (Figure 5) confirmed that the ten representative defects chosen were distributed throughout the foil. There was no obvious evidence for a correlation between the sensitivity of the image size of a defect to $g$ and $s_{g}$ and the depth of the defect in the foil.

- The most reliable information about the changes in the size of individual defects on annealing is likely to be obtained by taking a series of 5-7 micrographs with a systematic variation of deviation parameter from $0.2-0.3 \mathrm{~nm}^{-1}$. Such an experiment is described briefly in section 3 below.

\section{Low-temperature experiment}

Full details of this experiment will be given in a later publication [8]. Here we show how the modified weak-beam method discussed above can be used to obtain data on changes in cluster sizes in an in-situ ion irradiation and annealing experiment.

Again, irradiations were performed with $\mathrm{Cu}^{+}$ions of energy $600 \mathrm{keV}$. The specimens were irradiated in situ in an Hitachi-9000 electron microscope with the sample temperature held at $20 \mathrm{~K}$ in an Oxford Instruments low temperature holder. The same region was imaged 
using $g=002$, with $\mathrm{s}_{\mathrm{g}}$ varying from 0.18 to $0.3 \mathrm{~nm}^{-1}$. Defect sizes were measured from micrographs recorded at $20 \mathrm{~K}$, both before and after an isochronal anneal to $120 \mathrm{~K}$. It was hoped thereby to be able to deduce the interstitial or vacancy nature of a defect by its change in size following this anneal through the free interstitial migration Stage I. The results of measurements on four defects are shown in Figure 6. The first and second, defects 11 and 17, show no evidence for a change in size on annealing to $120 \mathrm{~K}$. Defect 11 shows a consistent size across the whole range of $s_{g}$. Defect 17 shows a larger variation in image sizes, although there seems to be consistency between the measurements of image size before and after the anneal to $120 \mathrm{~K}$ for equivalent values of $\mathrm{s}_{\mathrm{g}}$. These two types of behaviour were typical of a large majority of the defects measured. We can conclude that in most cases any change in loop size is too small to be detected - i.e. less than about $0.5 \mathrm{~nm}$. A few defects did show evidence of a size change. An example is defect 6 , where the image sizes after the anneal are consistently smaller (by about $1 \mathrm{~nm}$ ) than before the anneal for all but the smallest $\mathrm{s}_{\mathrm{g}}$. This evidence of shrinkage may imply that this loop is vacancy in nature. Vacancy loops would be expected to shrink by the absorption of freely-migrating interstitials in Stage I. Such behaviour was typical of a small fraction of the defects measured $(\approx 10 \%)$. Defect 12 , on the other hand, shows consistently larger image sizes after annealing, so providing evidence for loop growth. By the same argument given above, the likely nature of this loop is interstitial. Such behaviour was found in only 3 of 55 defects measured $(\approx 5 \%)$ so this conclusion must be regarded as tentative.

In this experiment, the most marked effect of annealing through Stage I was not in fact a change in defect sizes. Unexpectedly, a substantial fraction of clusters -roughly equal to the fraction which remained - disappeared entirely, and a similar number of others appeared. A judgement on the nature of these clusters cannot be made on the basis of the current experiment alone, but vacancy collapse, interstitial clustering, complete recombination, and 
loop movement all seem possible. Initial video experiments seem however to rule out the possibility of loop movement. Images gradually faded or appeared over periods of tens of seconds. Further experiments are in progress to explore this further.

\section{Conclusions}

1. We have made an experimental investigation of the weak-beam technique as applied to small clusters in copper, analysing images as functions of diffraction vector $\mathbf{g}$, deviation parameter $s_{g}$, and beam convergence angle. The image sizes depended on all these parameters, but the main sensitivity is to $\mathrm{s}_{\mathrm{g}}$. This result validates the warnings given in earlier publications [4-6] in the use of the weak-beam technique for size measurements of very small clusters. An obvious and important implication is that image size measurements should not be made from a single micrograph if the defect sizes are small (say less than $5 \mathrm{~nm})$. Defect experiments reported in the literature which employed only a single value of deviation from the exact Bragg two beam diffraction condition should therefore be viewed with great caution. The present work has shown however that defects in copper can be reliably revealed, throughout a foil thickness of $60 \mathrm{~nm}$, by taking a series of $5-7$ micrographs with a systematic variation of deviation parameter from $0.2-0.3 \mathrm{~nm}^{-1}$. The maximum image size for $\left|\mathrm{s}_{\mathrm{g}}\right| \geq 0.20 \mathrm{~nm}^{-1}$ can be measured to an accuracy of about $\pm 0.5 \mathrm{~nm}$ and may represent the best estimate of the true defect size.

2. The weak beam sizing technique described above was used to measure changes in defect sizes in copper, irradiated in situ in an Hitachi-9000 electron microscope with $\mathrm{Cu}^{+}$ions of energy $600 \mathrm{keV}$ with the sample temperature held at $20 \mathrm{~K}$. We looked for systematic changes in image sizes before and after an anneal to $120 \mathrm{~K}$. Most clusters showed no 
evidence for a change in size larger than the resolution limit of about $0.5 \mathrm{~nm}$. Of those defects whose measured size changes exceeded statistical error, the majority showed size

decreases, implying a vacancy nature. However, a small minority showed size increases and were judged, therefore, to be possibly interstitial in nature.

\section{Acknowledgements}

This work was supported supported by the US Department of Energy, BES-Materials Science, under DOE contract \# W-31-109-Eng-38. We thank E A Ryan, L Funk, A McCormick of the Argonne IVEM User Facility for technical assistance, L Funk and T LDaulton of ANL for help in preparing specimens, and $\mathrm{AK}$ McKnight of Oxford for photographic assistance.

\section{References}

[1] M L Jenkins, D J H Cockayne and M J Whelan,1973, J.Micr. 98, 155.

[2] M L Jenkins, 1974, Phil.Mag. 29, 813.

[3] M Horiki, S Arai, Y Satoh and M Kiritani, 1998, J. Nucl.Mat. 255, 165.

[4] F Häussermann, K-H Katerbau, M Rühle and M Wilkens, J.Micr. 98, 135.

[5] A Y Stathopoulos, 1981, Phil.Mag.A. 44, 285.

[6] ML Jenkins, 1994, J.Nucl.Mat. 216, 124.

[7] Y Satoh, H Taoka, S Kojima, T Yoshiie and M Kiritani, 1994, Phil.Mag.A70, 869

[8] M A Kirk, ML Jenkins and H Fukushima, 1998, submitted to MRS Fall Meeting, Boston, November 1998. 


\section{Figure legends:}

Figure 1. Weak-beam micrographs of the same field of defects taken with different values of the beam convergence. The beam convergence semi-angle ranges from $0.32^{\circ}$ to $0.16^{\circ}$ and is shown in each case at the bottom right. The diffraction patterns are shown inset. A set of 10 defects are labelled F.O.

Figure 2. Measured image sizes as a function of the convergence semi-angle for the set of ten labelled defects in Figure 1. For clarity these are shown on two graphs, each showing measurements of five defects.

Figure 3. A series of weak-beam micrographs corresponding to condition (ii), i.e. $\mathbf{g}=$ $002, s_{g}>0$, with $\left|s_{g}\right|$ ranging in 7 approximately equal steps from $0.15-0.29 \mathrm{~nm}^{-1}$. Values of $n$ in the ( $\mathrm{g}, \mathrm{ng})$ notation are also shown. The micrograph at the top left is a conventional darkfield two-beam image $\left(s_{g}=0, n=1\right)$. The ten defects analysed in detail are labelled $1-10$.

Figure 4. Measured image sizes for each of the defects 1-10 shown in Figure 3. The defects were imaged under each of the conditions (ii) - (v). Size measurements are shown for $\pm \mathrm{g}$ and as a function of $\mathrm{s}_{\mathrm{g}}$.

Figure 5. Schematic showing the depth in the foil of each of the defects $1-10$ of Figures 3 and 4 relative to other nearby defects, shown as squares (condition (vi)).

Figure 6. Size measurements on four defects in copper irradiated at $30 \mathrm{~K}$ with $\mathrm{Cu}^{+}$ions of energy $600 \mathrm{keV}$, before and after an anneal to $120 \mathrm{~K}$. The first two defects ( 11 and 17$)$ show 
no evidence of a size change. The second two ( 6 and 12) appear to shrink and grow respectively. 

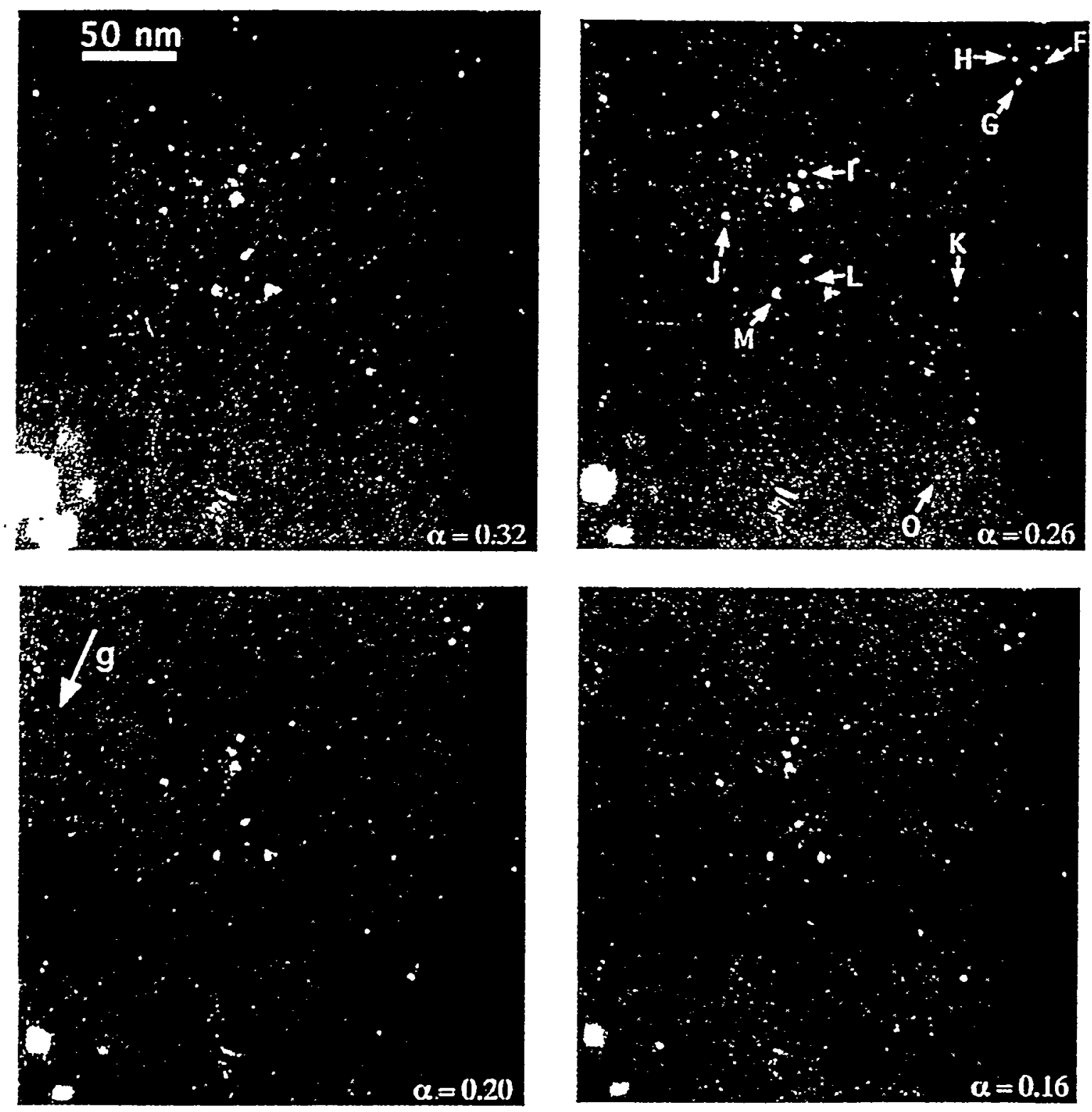

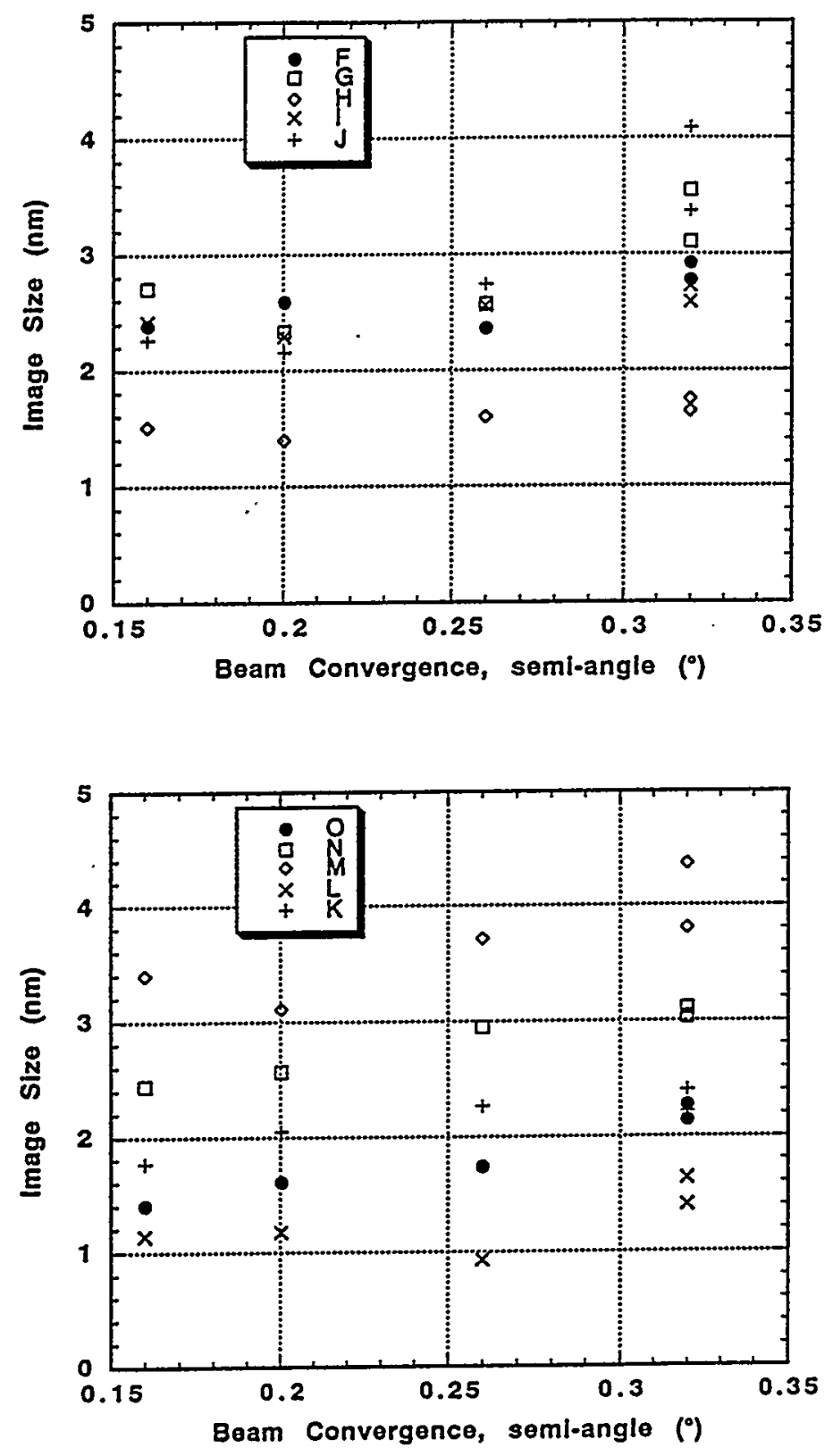

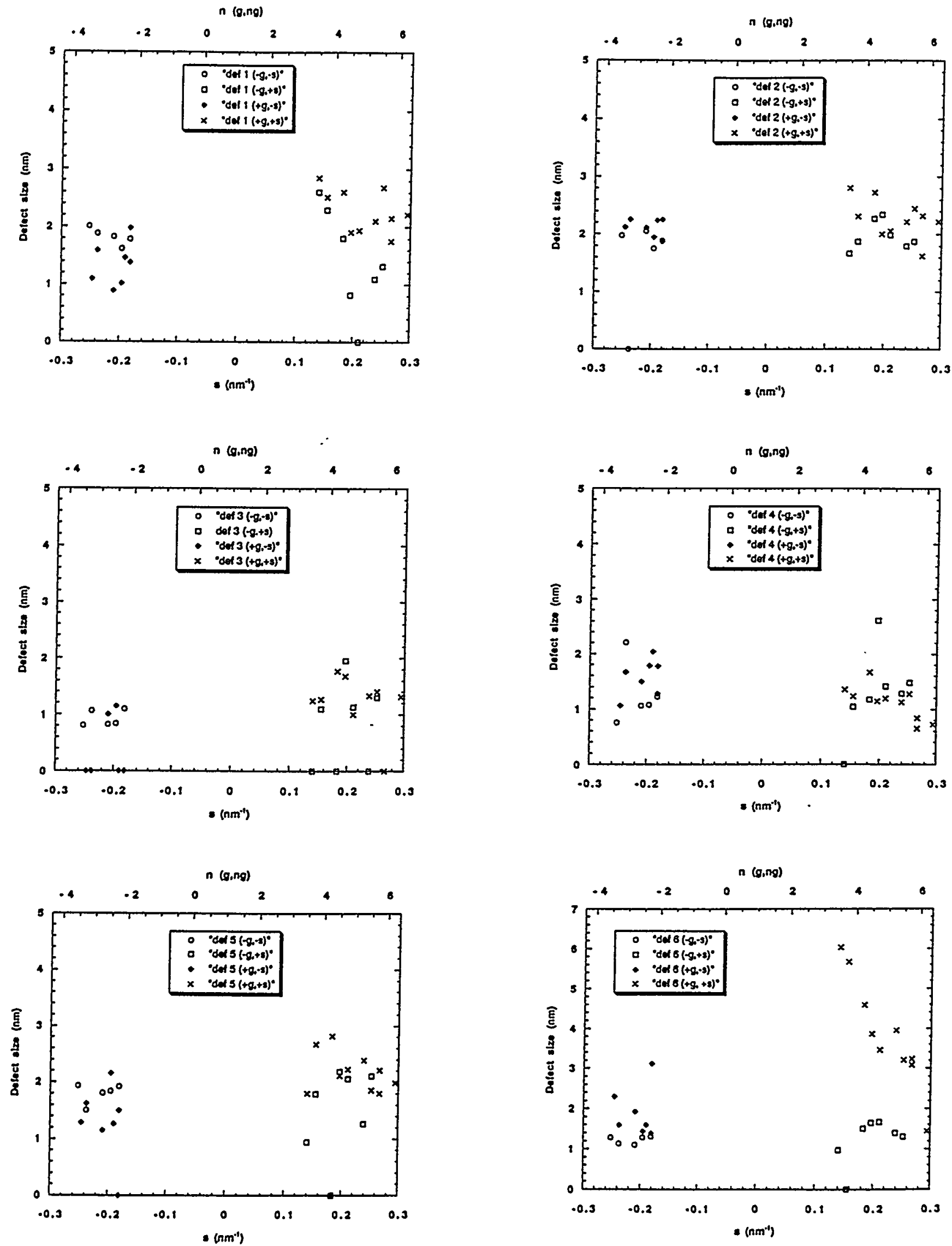


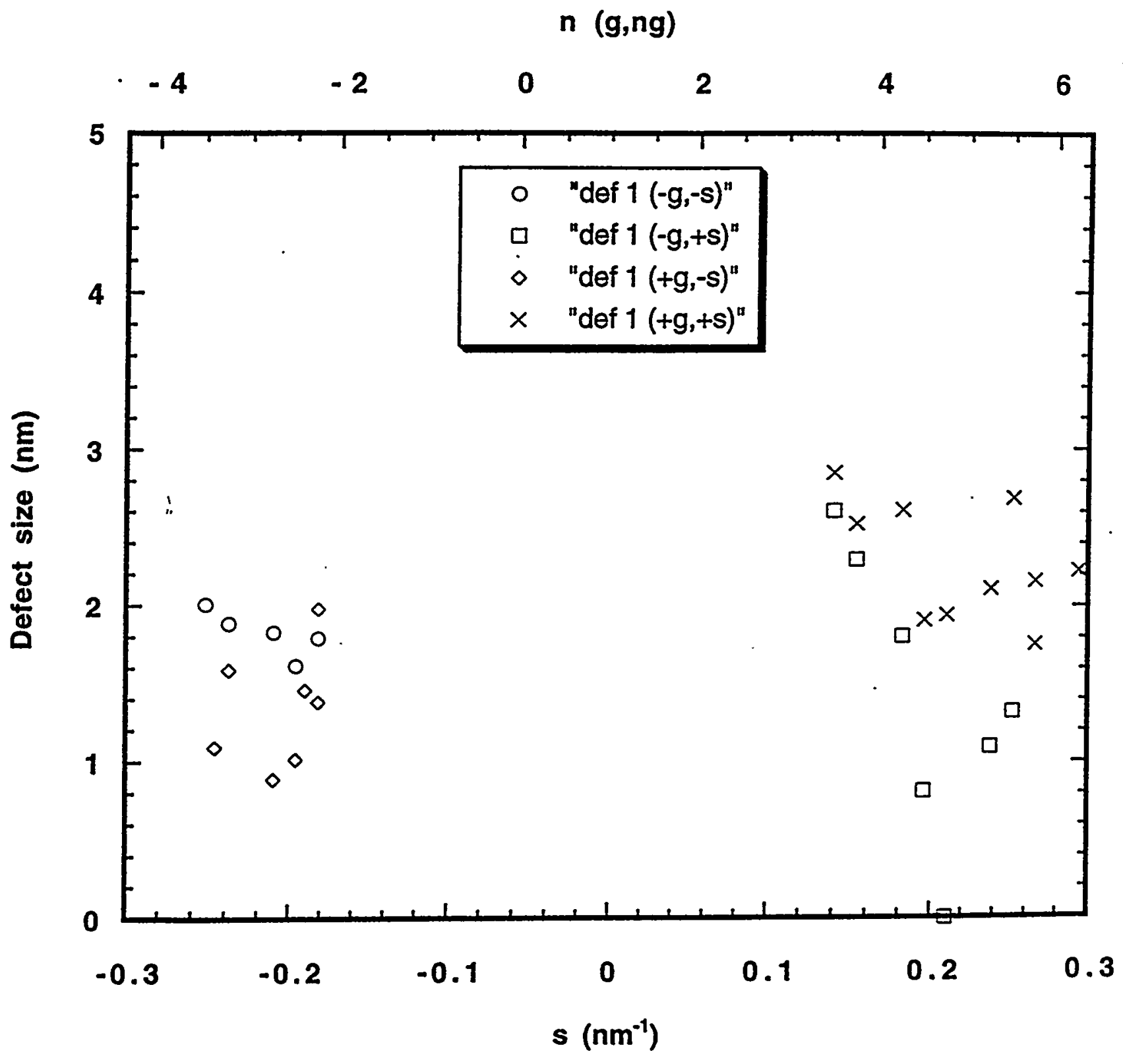



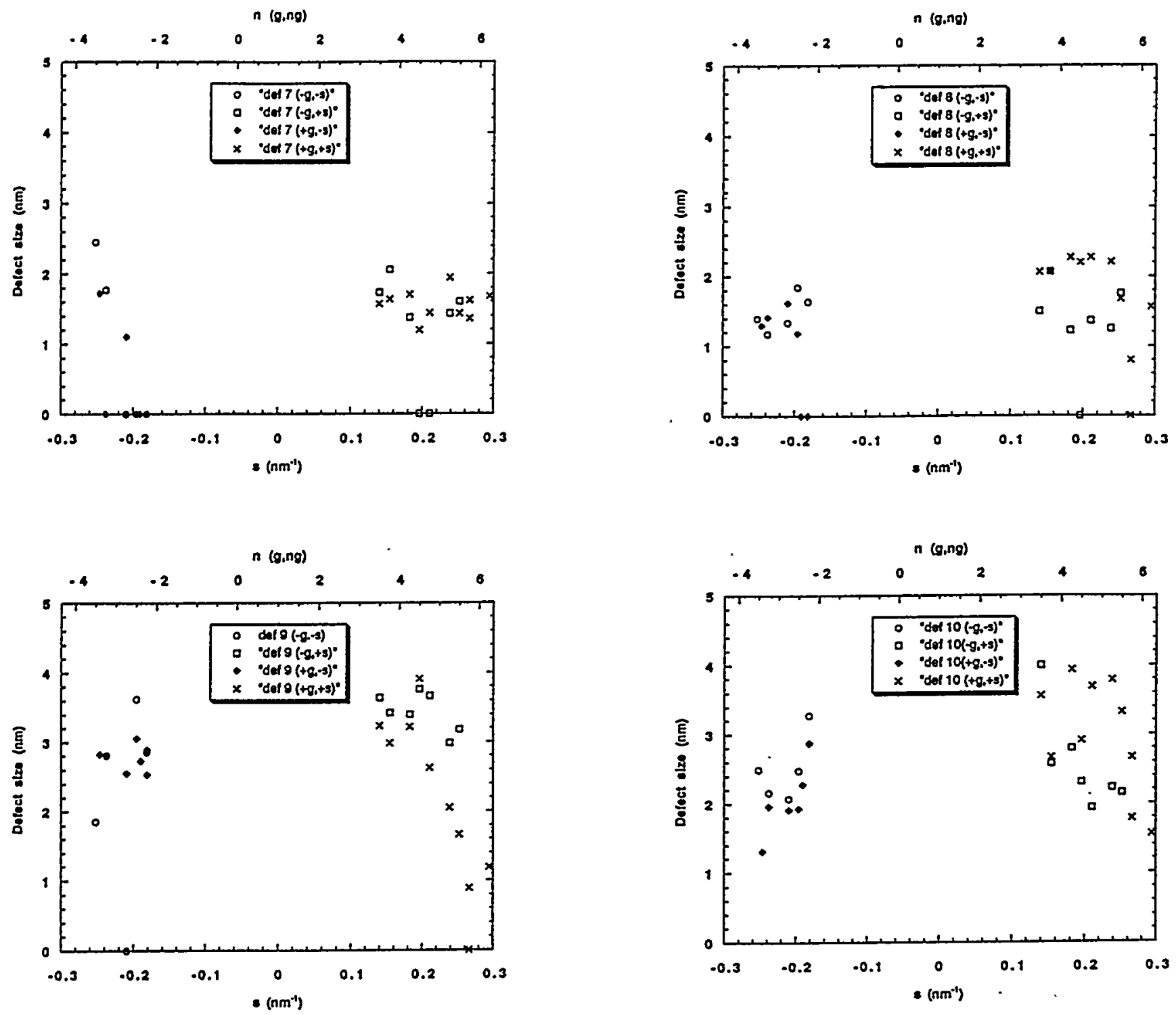


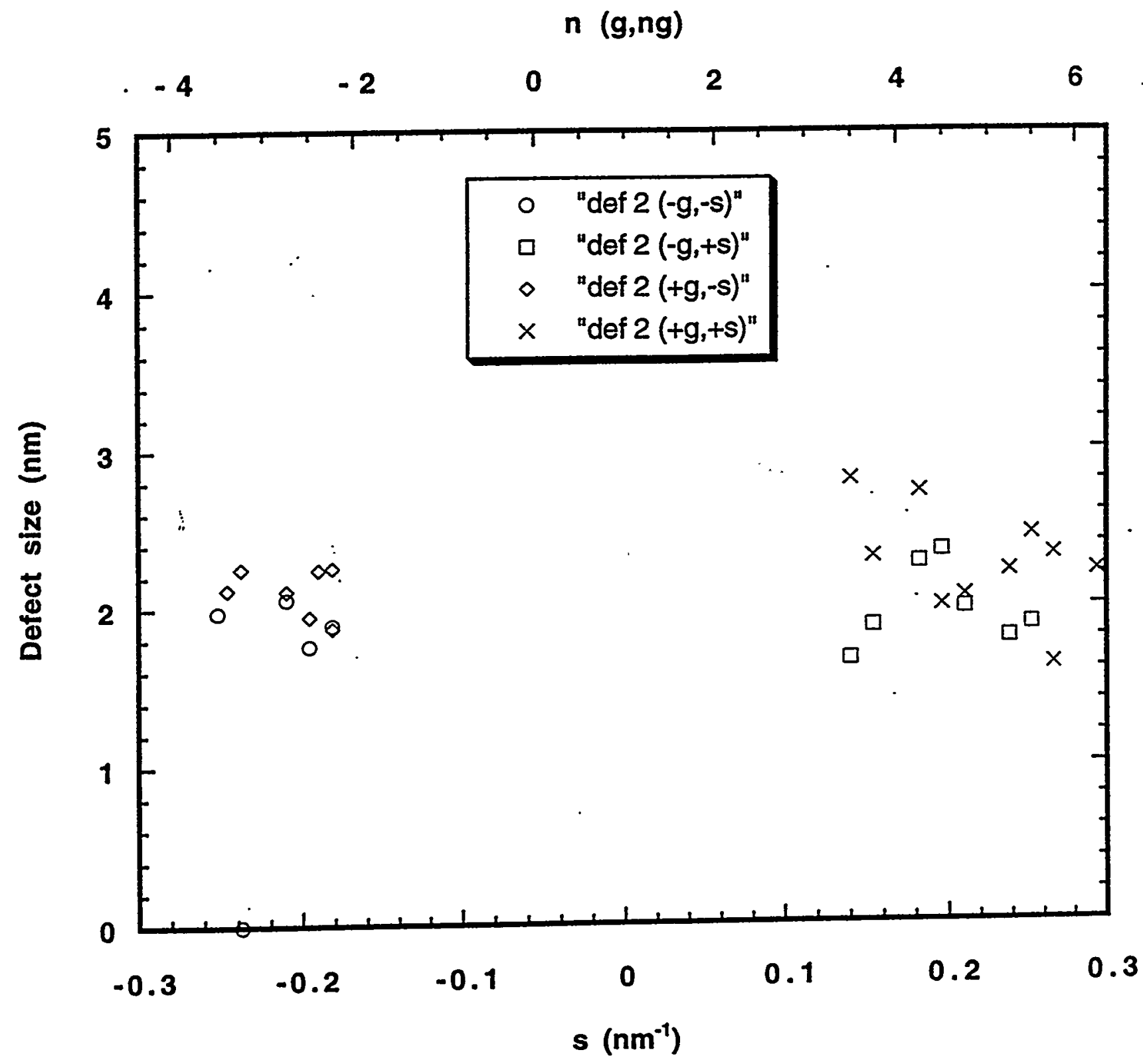




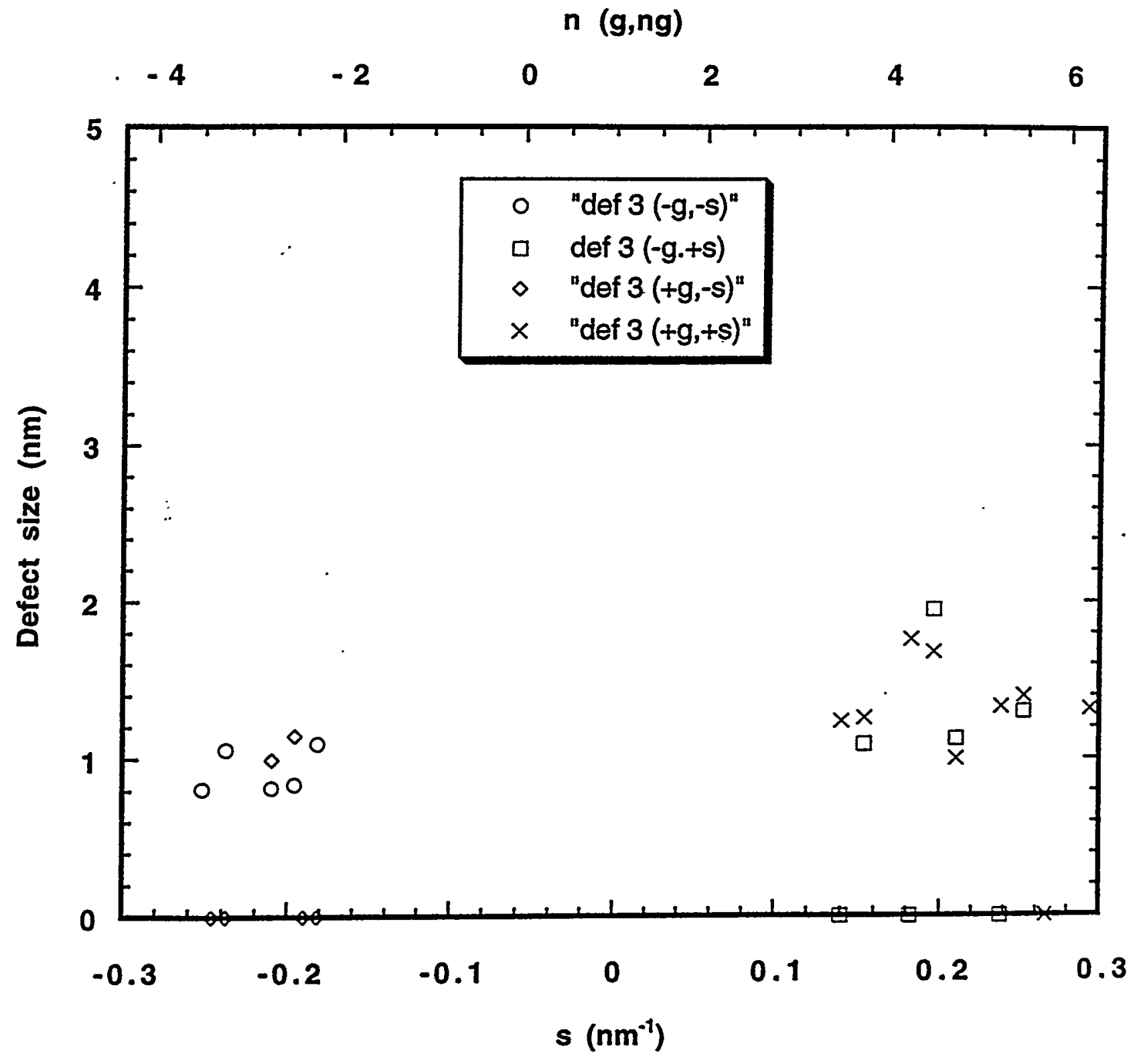




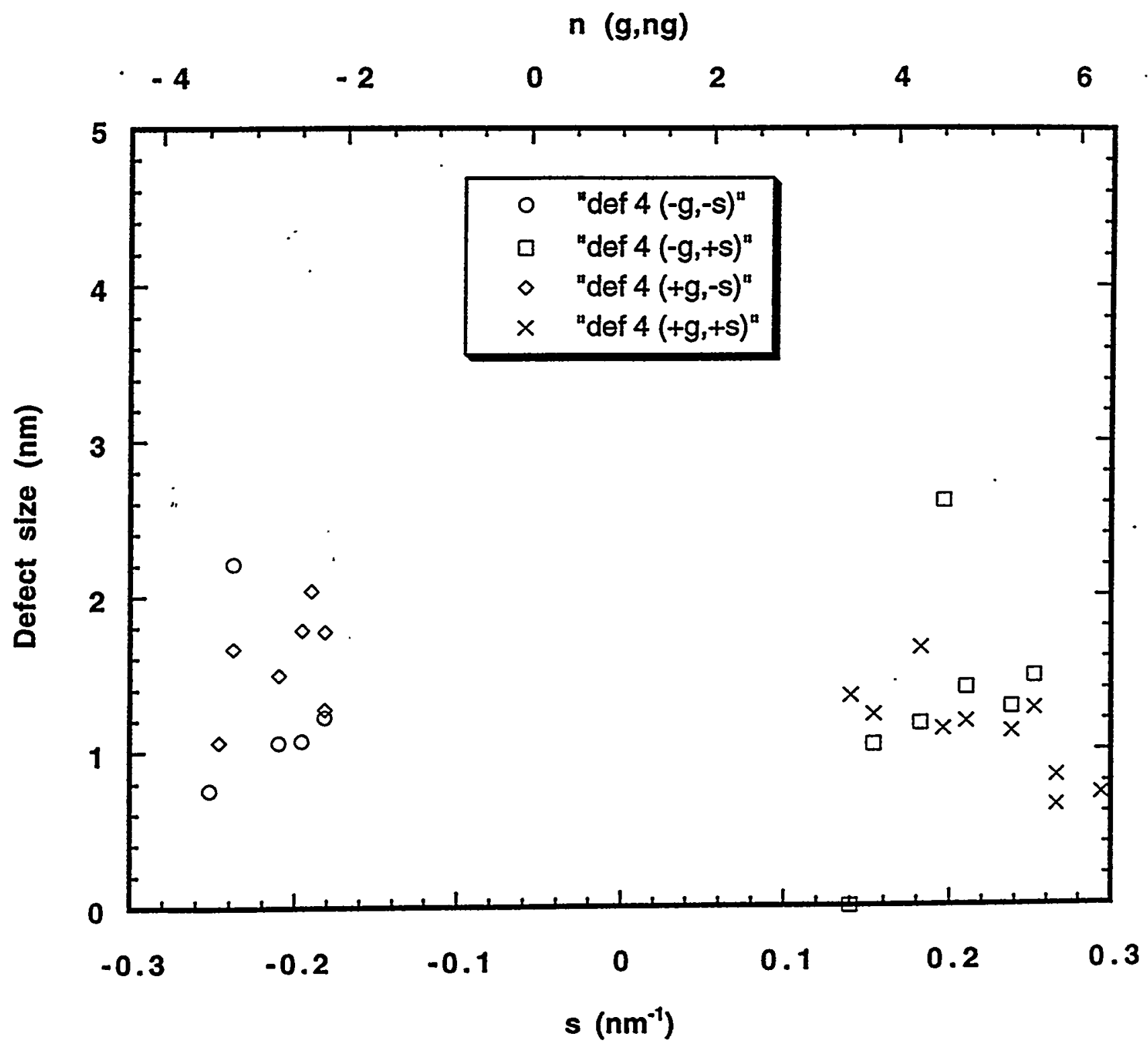




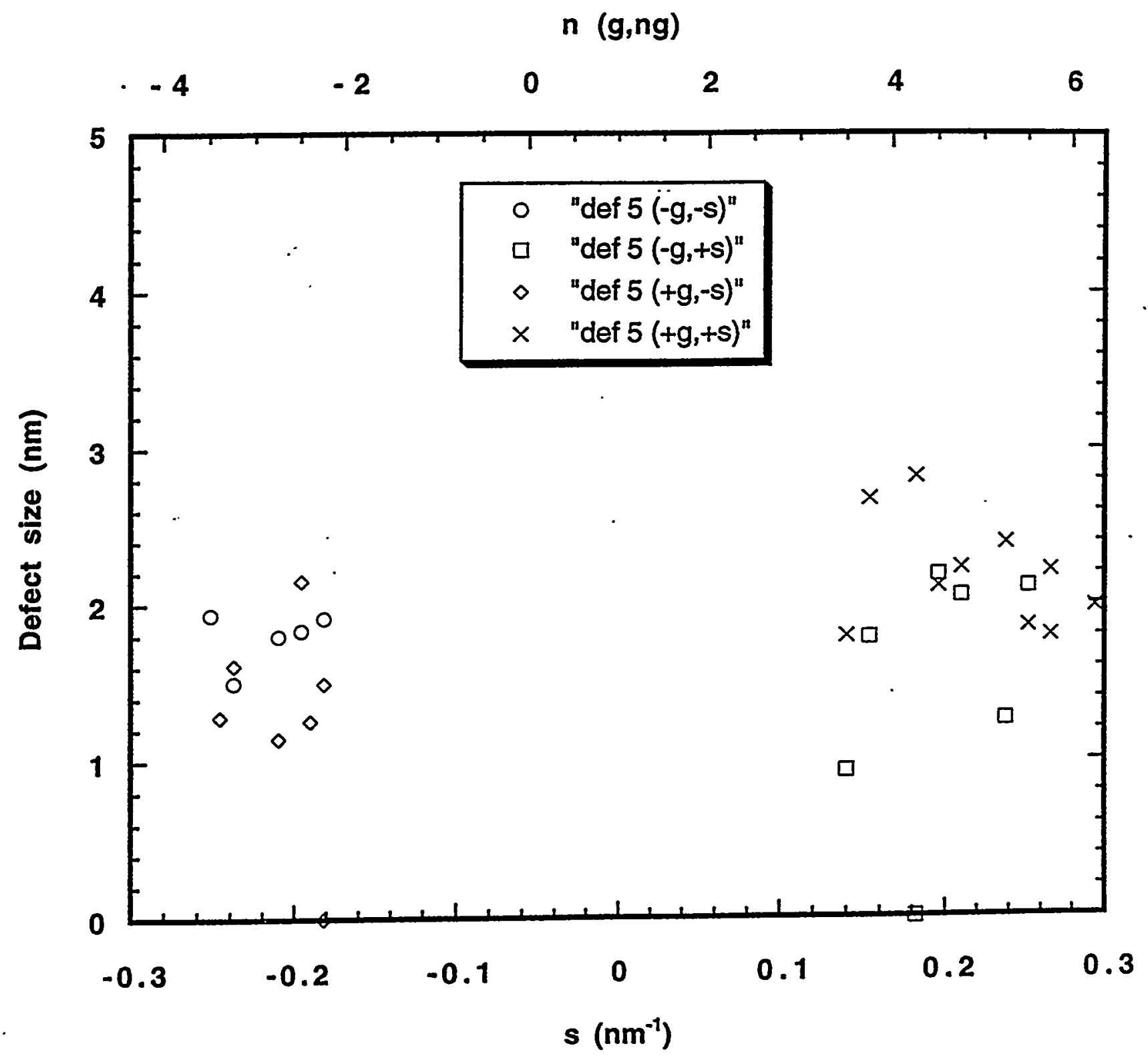




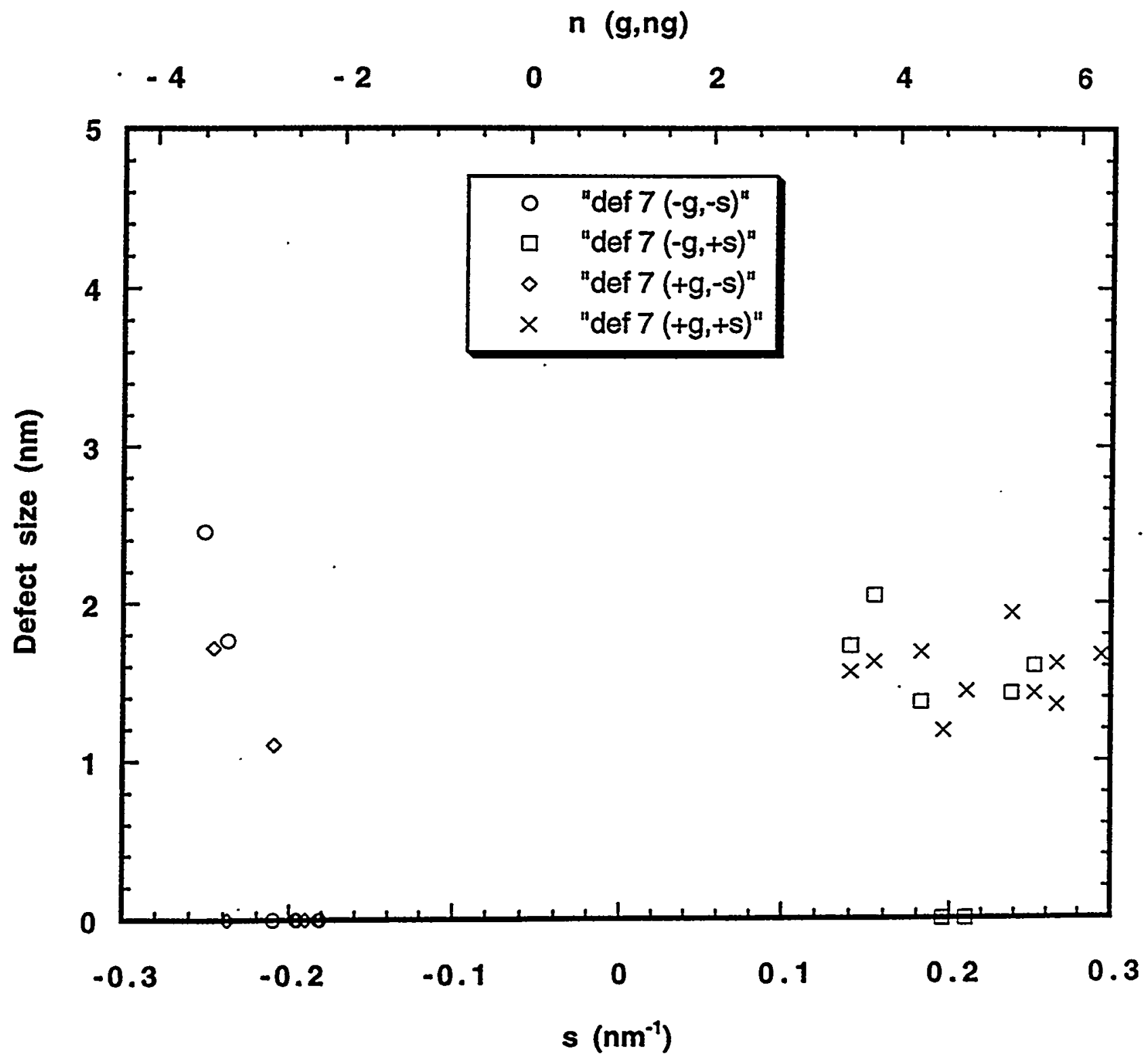




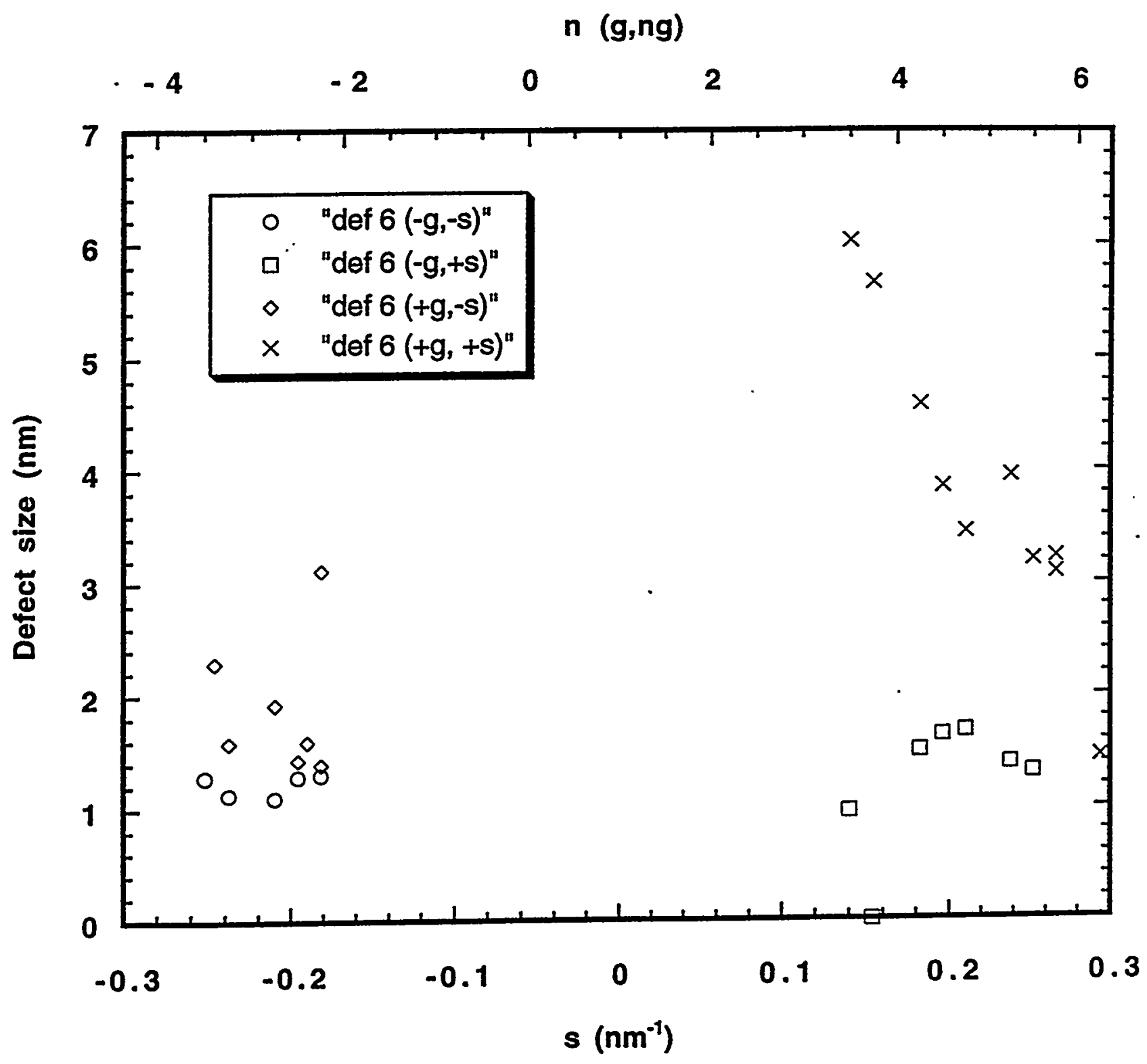




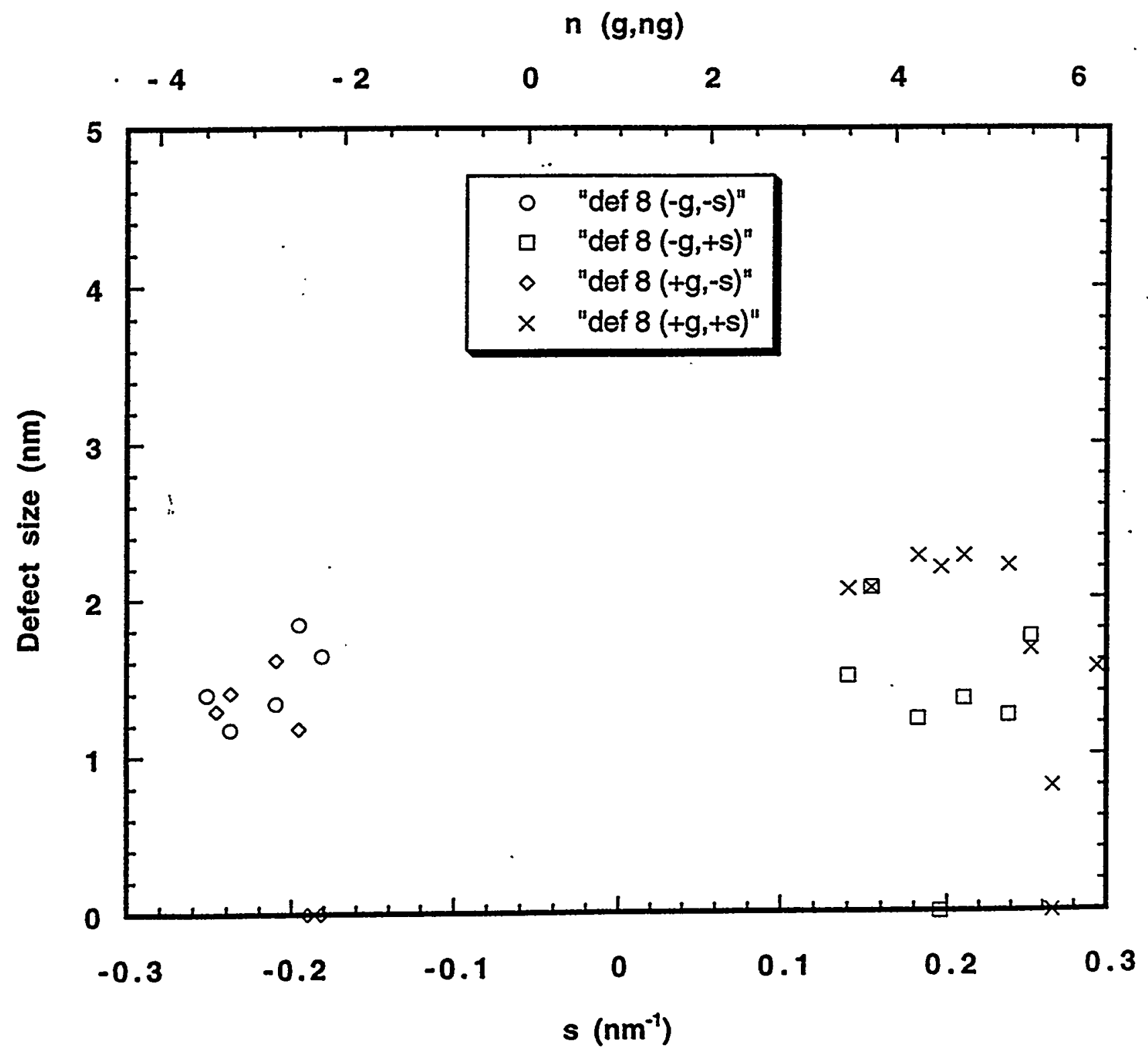

! 


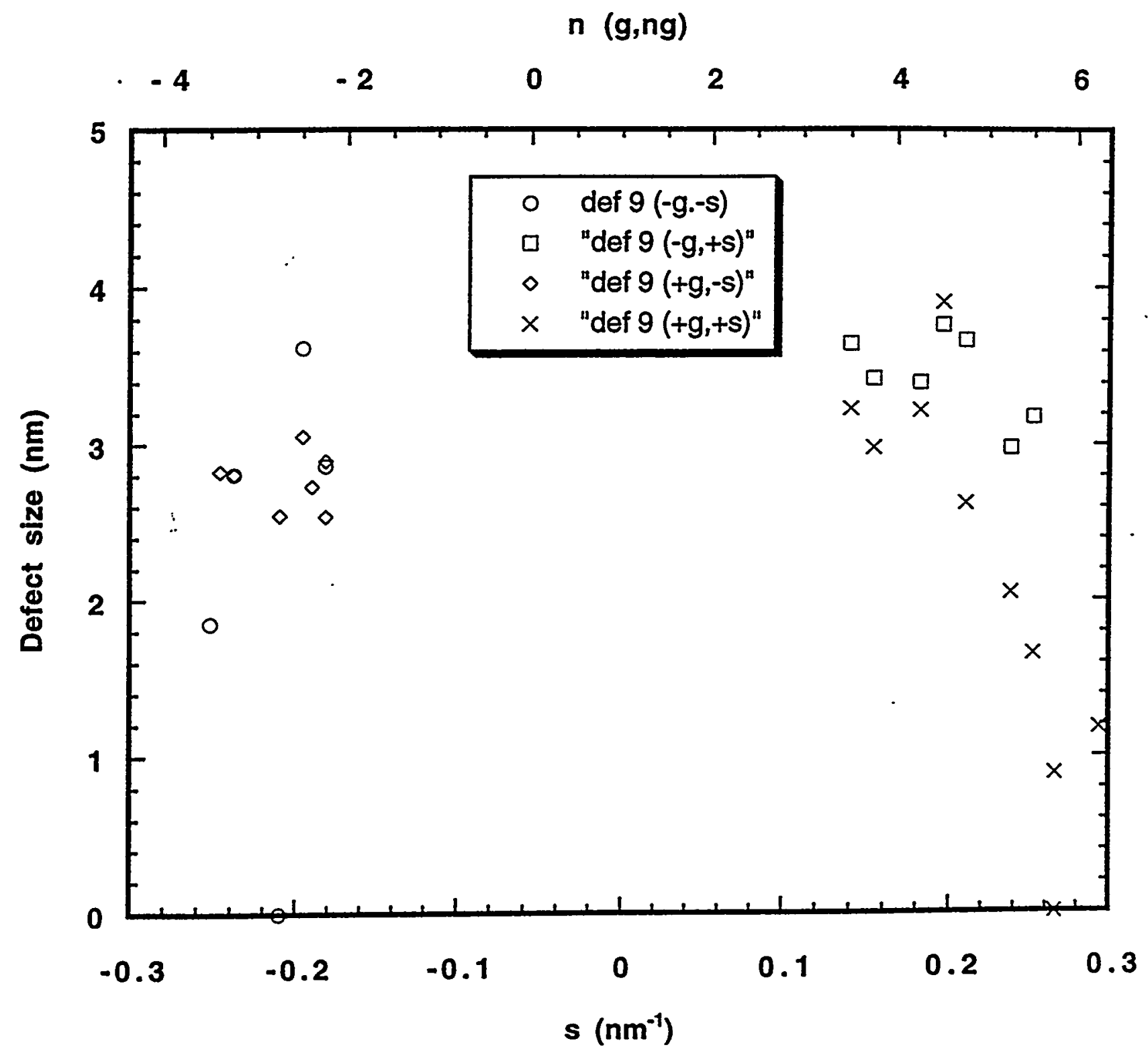




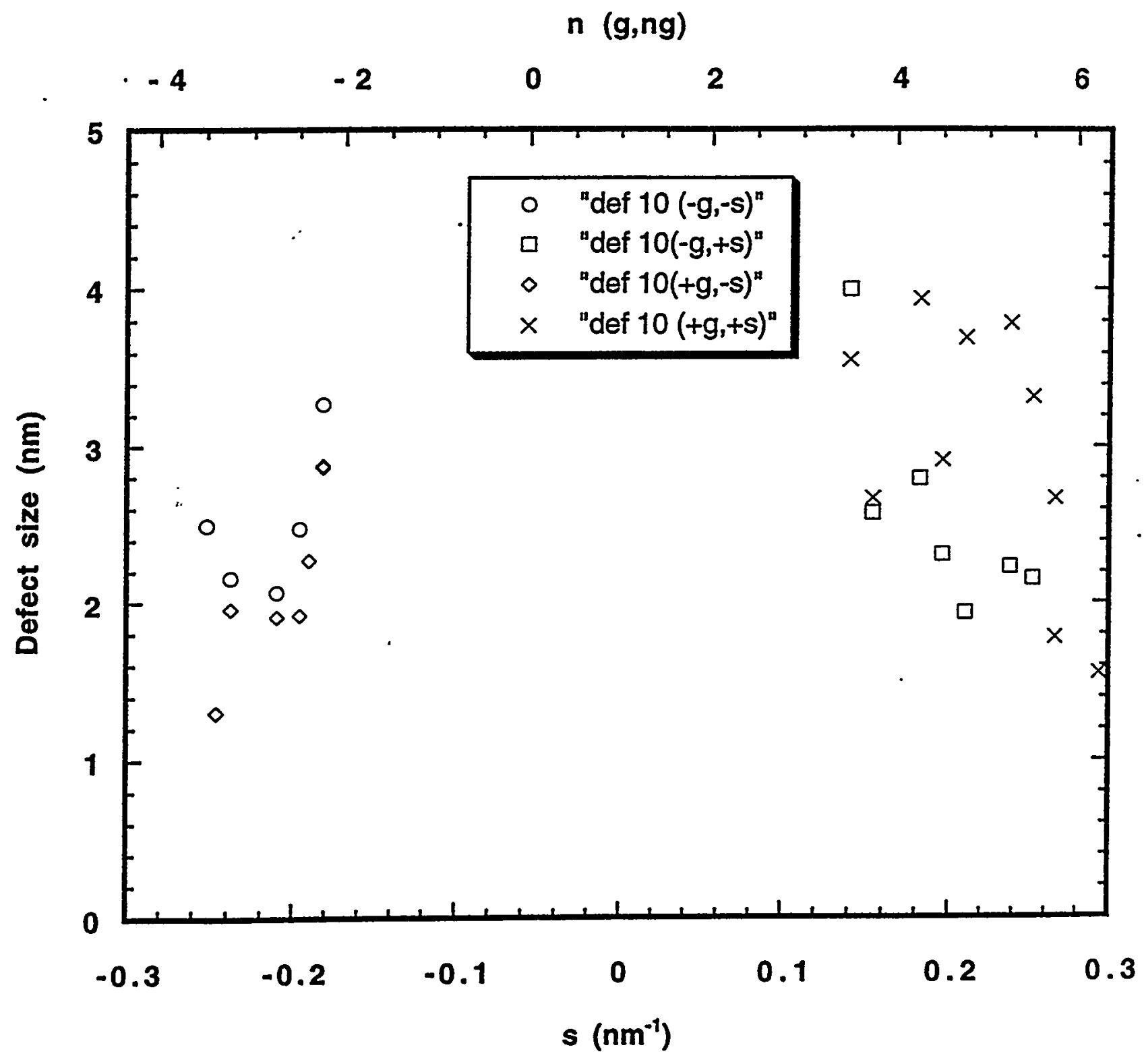




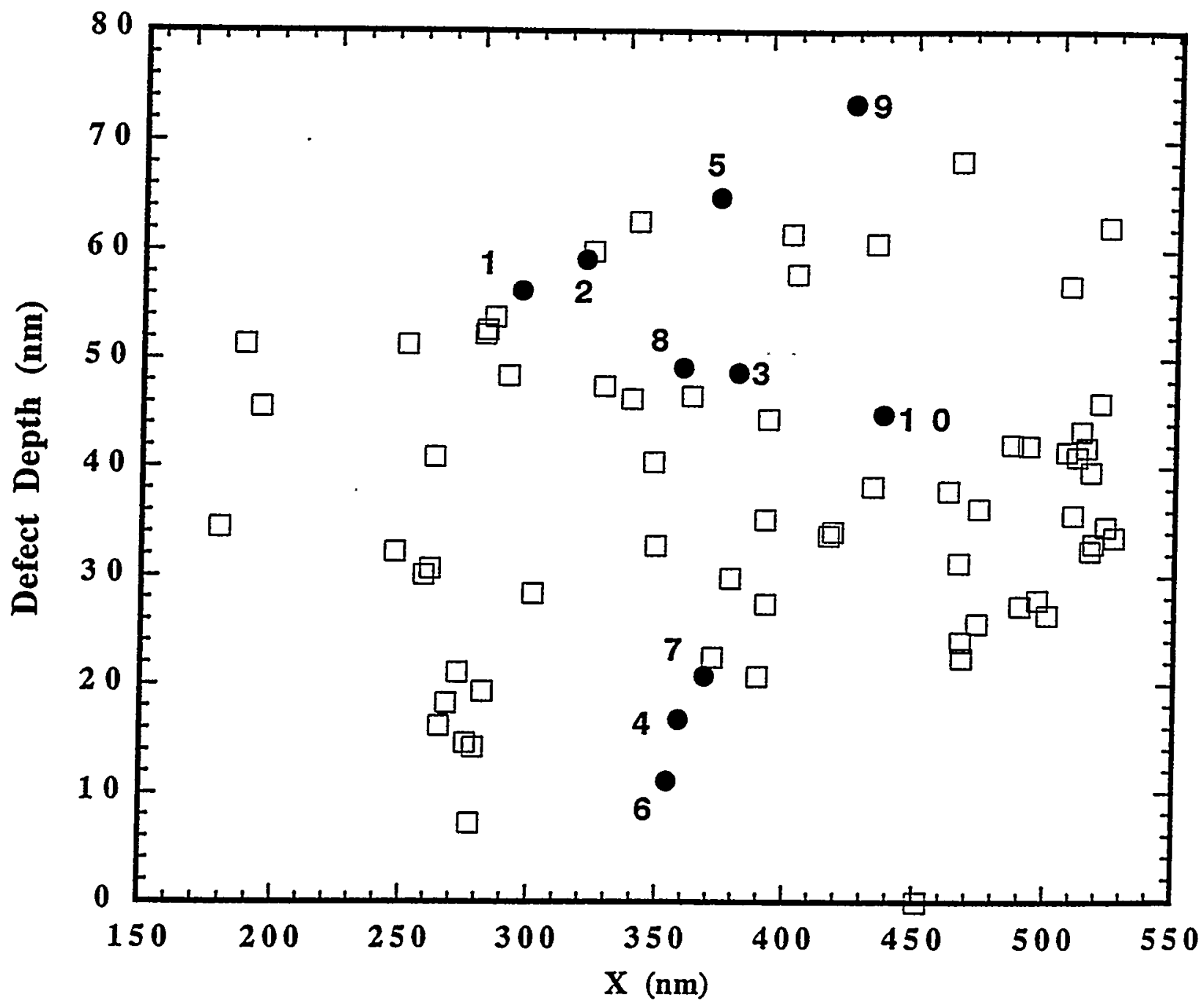



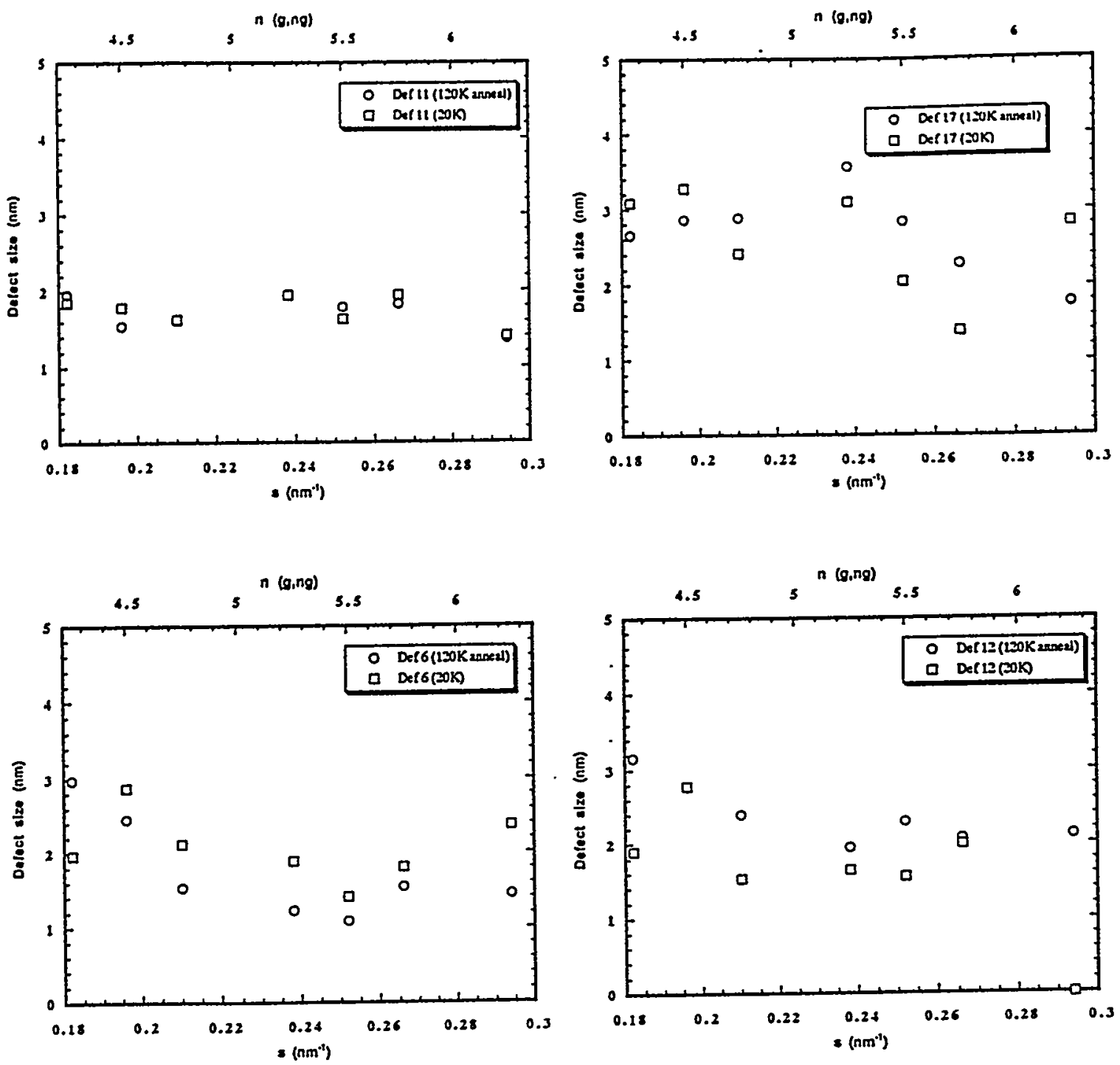


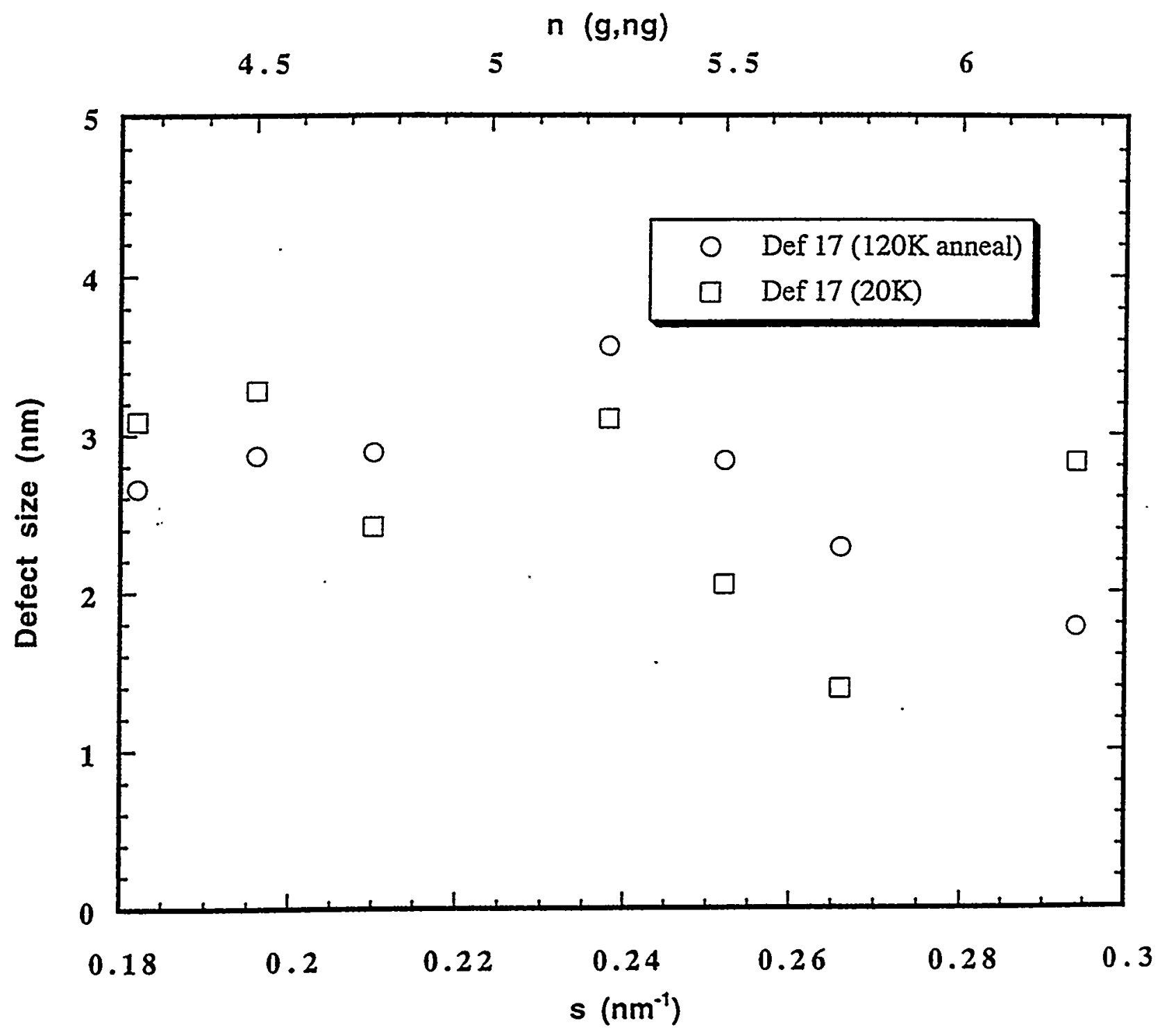




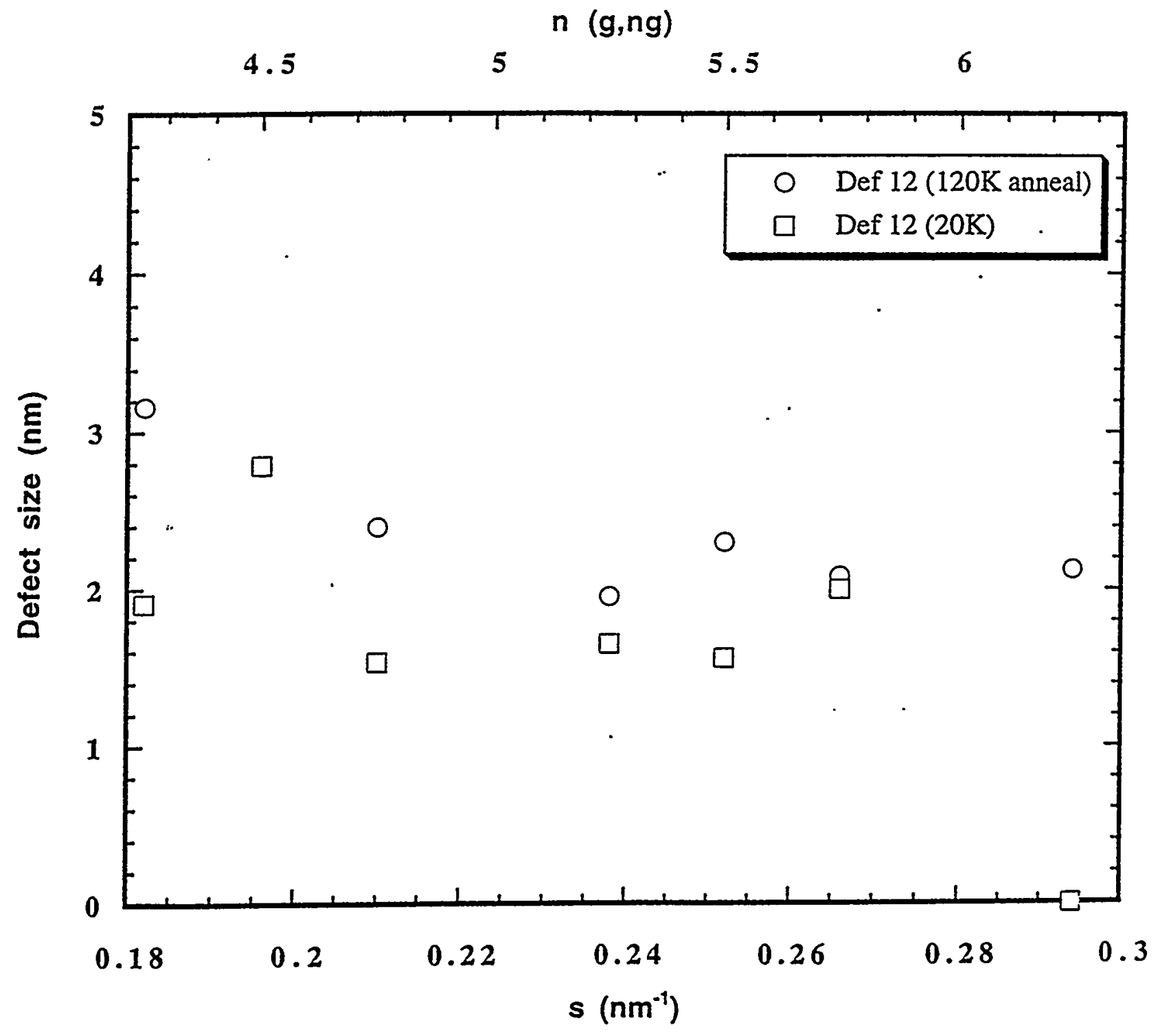




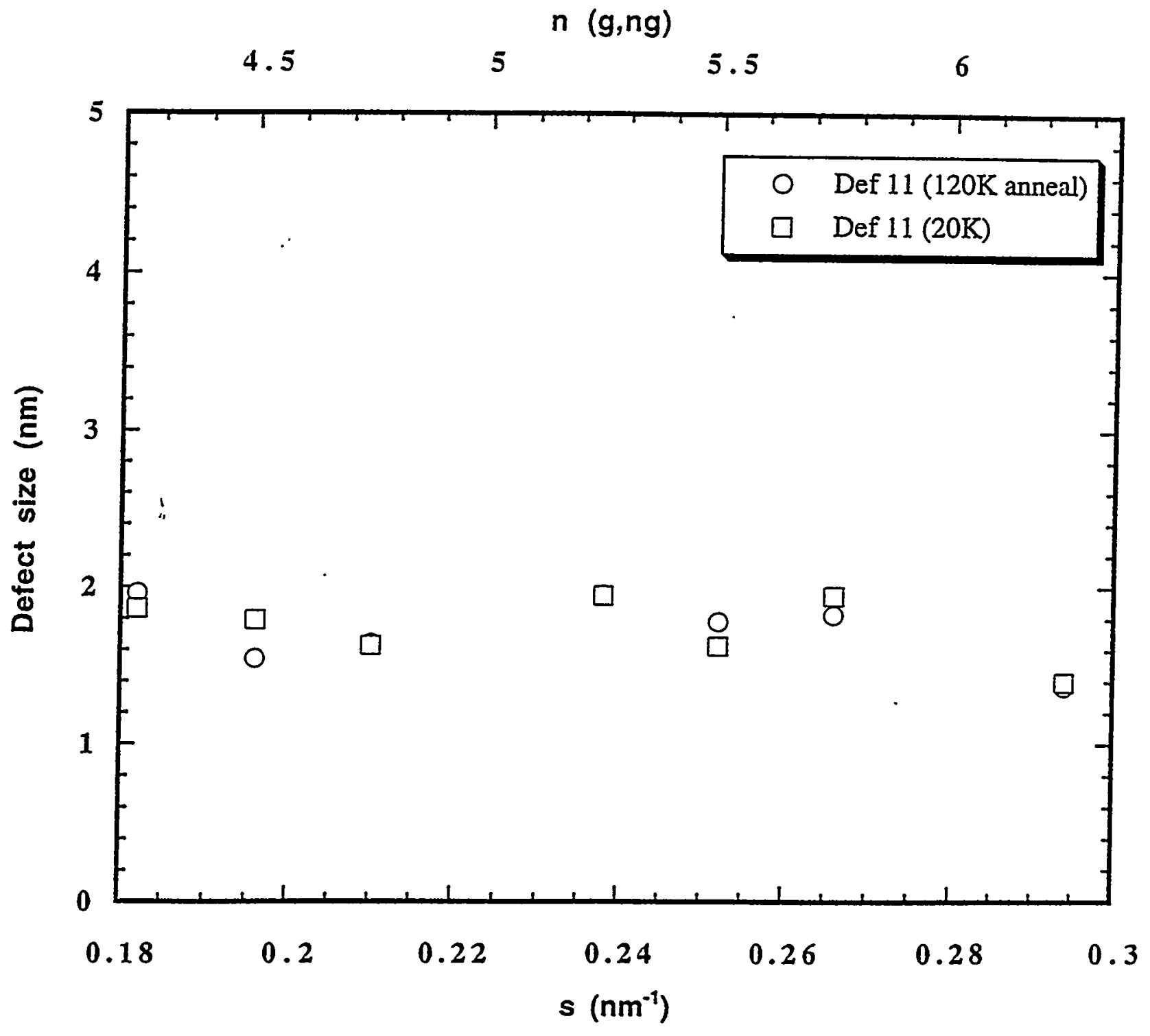




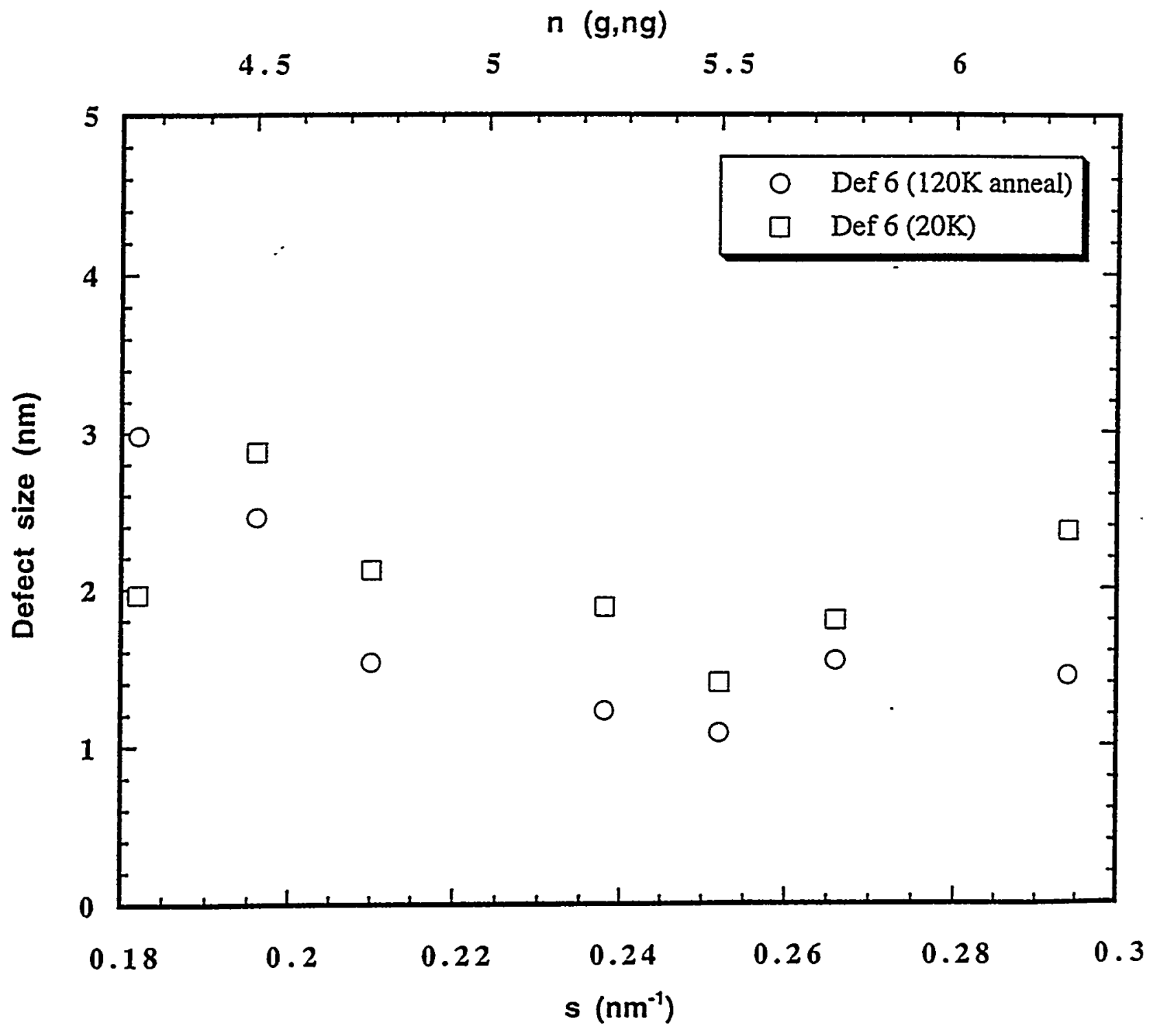

